DOI: $10.29303 /$ jrpb.v8i2.179

ISSN 2301-8119, e-ISSN 2443-1354

Tersedia online di http://jrpb.unram.ac.id

\title{
ANALISIS TEKNIK DAN UJI KINERJA REAKTOR KOMPOS PORTABLE (RK TEP-1401)
}

\author{
Technical Analysis and Performance Test of Portable Compost Reactor
} (RK TEP-1401)

\section{Wahyu K. Sugandi"), Zaida, Niar Suwiarti}

Program Studi Teknik Pertanian dan Biosistem Fakultas Teknologi Industri Pertanian Universitas Padjadjaran

Jl. Raya Bandung - Sumedang Km 21, Jatinangor, Sumedang, 45363, Indonesia

Email ${ }^{*}$ : sugandiwahyu@gmail.com

Diterima: Juli 2020

Disetujui: September 2020

\begin{abstract}
One equipment to treat organic waste into compost is a decomposing tank of waste reactor. Currently the Agriculture Equipment and Machinery Laboratory at the Department of Agriculture and Biosystem Engineering, Faculty of Agriculture Industrial Technology, Padjadjaran University has been developed a portable compost reactor (RK TEP-1401). However, the specification of this device has not been evaluated. The purpose of this research was to calculate the technical analiysis and performance test of portable compost reactor. The method used in this research was descriptive analysis method consist of observation, measurement, calculation, and technical analysis of portable compost reactors. Data analysis was also conducted to obtain equipment feasibility data by comparing calculated data with actual measurements. Furthermore, analysis of equipment performances (kamba speed, theoretical capacity, actual capacity, engine efficiency, vibration level, and noise level) were also conducted in this study. The material used was organic material in the form of leaves and dried twigs. The results of the technical analysis calculations were theoretical capacity of 1,439.20 kg/hour, shaft diameter of $22 \mathrm{~mm}$, nominal bearing life of 721,397 hours, required chain length of $0.703 \mathrm{~m}$, frame deflection of $4.03 \times 10^{-8} \mathrm{~mm}$, and welding strength to support load of 198,88 N. While the results of the tool performance showed that the bulk density of organic garbage was $247.20 \mathrm{~kg} / \mathrm{m}^{3}$, the actual capacity was $921.6 \mathrm{~kg} / \mathrm{hour}$, the efficiency of the tool was $64.03 \%$, the actual power requirements were 215.94 watts, instrument noise level was $62.63 \mathrm{~dB}$, and reactor vibration level was $4.4 \mathrm{~mm} / \mathrm{s}$.
\end{abstract}

Keywords: compost reactor portable; performance test; technical analysis 


\begin{abstract}
ABSTRAK
Salah satu alat pengolah sampah organik menjadi kompos adalah tangki pengurai atau reaktor sampah. Saat ini Laboratorium Alat dan Mesin Pertanian Progam Studi Teknik Pertanian dan Biosistem telah mengembangkan alat reaktor kompos portable (RK TEP-1401) yang dapat mengolah sampah organik menjadi kompos. Namun, alat tersebut belum diketahui spesifikasinya. Tujuan penelitian ini adalah menghitung kelayakan teknik yang meliputi analisis poros, analisis rangka, analisis bantalan, analisis las, analisis bantalan, dan uji kinerja alat reaktor kompos portable agar diketahui spesifikasi teknisnya. Metode penelitian yang digunakan adalah metode analisis deskriptif, yaitu melakukan pengamatan, pengukuran dan perhitungan analisis teknik. Analisis data dilakukan untuk memperoleh data kelayakan mesin dengan membandingkan data hasil perhitungan dan pengukuran aktual. Selain itu, analisis kinerja mesin (meliputi kerapatan kamba, kapasitas teoritis, kapasitas aktual, efisiensi mesin, tingkat getaran dan tingkat kebisingan) juga dilakukan pada penelitian ini. Bahan yang digunakan adalah bahan organik berupa sisa - sisa daun, ranting yang sudah mengering. Hasil perhitungan analisis teknis terhadap alat reaktor kompos portable adalah kapasitas teoritis 1.439,20 kg/jam, diameter poros $22 \mathrm{~mm}$, umur nominal bantalan 2139 jam, panjang rantai yang dibutuhkan $0,703 \mathrm{~m}$, lendutan pada rangka $4,03 \times 10^{-8} \mathrm{~mm}$, dan kekuatan las untuk menopang beban 198,88 N. Sedangkan hasil kinerja alat menunjukkan bahwa kerapatan kamba sampah organik $247,20 \mathrm{~kg} / \mathrm{m}^{3}$, kapasitas aktual alat 921,6 kg/jam, efisiensi alat 64\%, kebutuhan daya aktual 215,94 watt, tingkat kebisingan alat sebesar 62,63 dB, dan tingkat getaran reaktor $4,4 \mathrm{~mm} / \mathrm{s}$.
\end{abstract}

Kata kunci: analisis teknik; reaktor kompos portable; uji kinerja

\section{PENDAHULUAN}

Sampah rumah tangga merupakan limbah yang sudah tidak memiliki manfaat lagi dan harus di kelola dengan baik sehingga tidak membahayakan lingkungan (Kastaman, Kramadibrata, 2007). Sampah tersebut adalah sisa kegiatan sehari-hari manusia berupa bahan organik dan non organik yang dibuang ke lingkungan.

Jumlah sampah dipengaruhi oleh beberapa faktor salah satunya adalah perkembangan dan pertumbuhan penduduk. Pesatnya perkembangan dan pertumbuhan penduduk akan sebanding dengan peningkatan aktivitas manusia khususnya di daerah perkotaan. Berdasarkan data dari PD Kebersihan Kota Bandung sampah di Kota Bandung umumnya didominasi oleh tumpukan sampah organik sebesar 52\% sedangkan $48 \%$ adalah sampah non organik. Untuk mengurangi sampah tersebut maka dibutuhkan pengelolaan sampah yang sesuai dengan jenis sampah. Saat ini pengelolaan sampah masih terbatas pada pengelolaan sampah non organik, yaitu dengan 3R (Reduce, Reuse dan Recycle). Sementara untuk sampah organik, umumnya dikelola untuk pembuatan kompos (Crawford, 2003)

Salah satu alat yang mempermudah pengelolaan sampah organik untuk pembuatan kompos adalah tangki pengurai atau lebih dikenal dengan reaktor sampah. Proses penguraian dengan menggunakan reaktor kompos membutuhkan waktu 38 hingga 41 hari dengan skala industri. Sehingga dibutuhkan reaktor sampah yang lebih mudah digunakan oleh masyarakat.

Berdasarkan permasalahan berkenaan dengan sampah organik, Laboratorium Alat dan Mesin Pertanian Program Studi Teknik Pertanian dan Biosistem Fakultas Teknologi Industri Pertanian Universitas Padjadjaran telah mengembangkan alat reaktor kompos portable (RK TEP-1401) (Gambar 1). Reaktor kompos portable ini memiliki tuas pengaduk 
(agitator) untuk mengaduk sampah organik, sehingga bahan akan tercampur merata. Selain itu, alat ini digerakkan dengan tenaga manusia sehingga hemat energi Namun, reaktor kompos portable ini belum memiliki spesifikasi alat, sehingga perlu dilakukan penelitian berkenaan dengan reverse engineering dan uji kinerja alat.

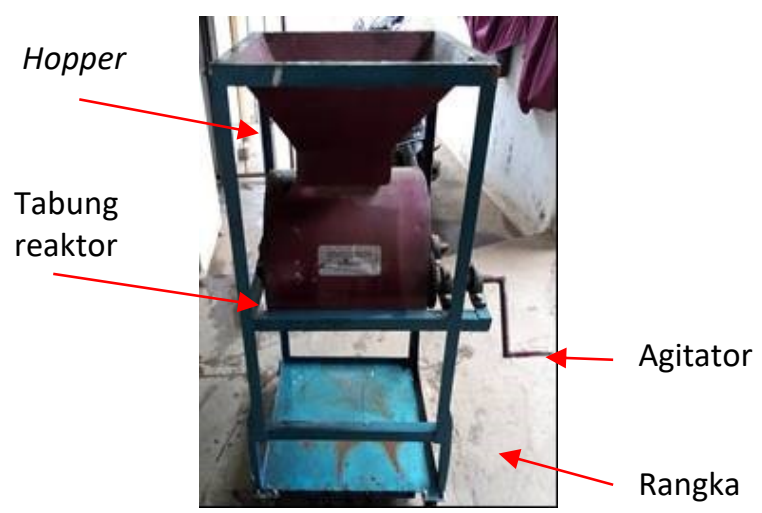

Gambar 1. Reaktor Kompos Portable

\section{METODE PENELITIAN}

Metode penelitian yang digunakan adalah metode analisis deskriptif, yaitu melakukan pengukuran, pengamatan dan perhitungan terhadap reaktor kompos portable kemudian menganalisis dari data tersebut sehingga diperoleh data spesifikasi alat. Alat yang digunakan pada penelitian ini adalah sound level meter, heart rate meter, vibration meter, timbangan, dan meteran. Adapun bahan yang digunakan adalah sisa sisa daun dan ranting yang sudah mengering.

\section{Analisis Teknik}

Analisis teknik meliputi perhitungan poros, bantalan, unit transmisi, kekuatan rangka dan kekuatan las. Adapun tahap pertama dalam analisis teknik alat ini adalah pengumpulan bahan organik untuk kemudian dimasukkan ke dalam hopper. Setelah melalui hopper, bahan akan masuk ke dalam silinder. Bahan aktif bioaktivator lalu dimasukkan ke dalam silinder agar bercampur dengan bahan organik. Silinder diputar dengan menggunakan agitator secara manual agar pengadukan merata. Bahan lalu didiamkan selama 21 hari agar terjadi dekomposisi menjadi kompos.

\section{Analisis Poros}

Besarnya diameter poros reaktor kompos portable (RK TEP-1401) dapat dihitung dengan Persamaan 1 (Sularso \& Suga, 1978).

$\mathrm{D}_{\mathrm{s}}^{3}=\frac{16}{(\pi)\left(\mathrm{S}_{\mathrm{s}}\right)} \sqrt{\left(\mathrm{K}_{\mathrm{b}} \mathrm{xM} \mathrm{M}_{\mathrm{b}}\right)^{2}+\left(\mathrm{K}_{\mathrm{t}} \mathrm{xM} \mathrm{M}_{\mathrm{t}}\right)^{2}}$

Dimana:

Ds $=$ Diameter poros $(\mathrm{mm})$

$\mathrm{Kb}=$ Faktor koreksi momen lentur

$\mathrm{Mb}=$ Momen lentur maksimal $(\mathrm{Nm})$

$\mathrm{Kt}=$ Faktor koreksi momen puntir

$\mathrm{Mt}=$ Momen torsi $(\mathrm{Nm})$

$\mathrm{Ss}=$ Tegangan geser $(\mathrm{Pa})$

\section{Analisis Bantalan}

Adapun untuk perhitungan bantalan reaktor kompos portable (RK TEP-1401) sesuai Persamaan 2 (Sularso \& Suga, 1978).

$\mathrm{f}_{\mathrm{h}}=\mathrm{f}_{\mathrm{n}} \times \frac{\mathrm{C}}{\mathrm{Pr}_{\mathrm{r}}}$

Dimana:

$\mathrm{f}_{\mathrm{h}} \quad=$ Faktor umur

$\mathrm{C}=$ Beban nominal dinamis spesifik $(\mathrm{kg})$

$P_{r}=$ Beban ekuivalen dinamis $(\mathrm{kg})$

Sedangkan umur teknis bantalan dapat dihitung dengan Persamaan 3 (Sularso \& Suga, 1978).

$\mathrm{L}_{\mathrm{h}}=500 . f_{h}{ }^{3}$

\section{Analisis Unit Transmisi}

Mekanisme sistem transmisi yang digunakan adalah perbandingan transmisi roda gigi-rantai sesuai Persamaan 4 (Sularso, \& Suga, 1978).

$\mathrm{i}=\frac{\mathrm{n}_{1}}{\mathrm{n}_{2}}=\frac{\mathrm{D}_{2}}{\mathrm{D}_{1}}$ 
Dimana:

$\mathrm{i}=$ Rasio Transmisi

$\mathrm{n}=$ kecepatan putar (rpm)

$\mathrm{D}=$ Diamater sproket $(\mathrm{mm})$

Adapun panjang sabuk dapat dihitung sesuai Persamaan 5.

$\mathrm{L}=2 \mathrm{C}+\frac{\pi}{2}\left(\mathrm{D}_{2}+\mathrm{D}_{1}\right)+\frac{1}{4 \mathrm{C}}\left(\mathrm{D}_{2}-\mathrm{d}_{1}\right)^{2}$

\section{Analisis Kekuatan Rangka}

Perhitungan rangka mengacu pada lendutan dan beban kritis yang diizinkan. Lendutan rangka dapat diketahui dengan menggunakan Persamaan 6 (Singer, et al., 1995).

$\delta=\frac{\mathrm{PL}^{3}}{48 \mathrm{EI}}$

Dimana:

$\delta=$ Lendutan $(\mathrm{mm})$

$\mathrm{P}=$ Beban yang bekerja pada rangka $(\mathrm{kg})$

$\mathrm{L}=$ Panjang kolom baris $(\mathrm{mm})$

$\mathrm{E}=$ Modulus elastisitas rangka $\left(\mathrm{kg} / \mathrm{mm}^{2}\right)$

$\mathrm{I}=$ Momen inersia rangka $\left(\mathrm{mm}^{4}\right)$

Hasil tersebut kemudian dibandingkan dengan lendutan izin sesuai Persamaan 7.

$\delta_{\text {izin }}=\frac{1}{300} \mathrm{~L}$

Kolom jari-jari girasi dihitung dengan menggunakan Persamaan 8.

$\mathrm{k}=\sqrt{\frac{\mathrm{I}}{\mathrm{A}}}$

Dimana:

$\mathrm{k}=$ Jari-jari girasi

$\mathrm{I}=$ Momen inersia $\left(\mathrm{m}^{4}\right)$

$\mathrm{A}=$ Luas permukaan batang rangka $\left(\mathrm{m}^{2}\right)$

\section{Analisis Kekuatan Las}

Perhitungan las pada pada rangka sesuai sesuai Persaman 9 (Singer, et al., 1995).

$\mathrm{F} \leq \tau . \mathrm{t} . \mathrm{l}$
Dimana:

$\mathrm{F}=$ Gaya yang bekerja pada rangka $(\mathrm{N})$

$\tau=$ Tegangan izin $\left(\mathrm{N} / \mathrm{m}^{2}\right)$

$\mathrm{t}=$ Tebal bidang las $(\mathrm{m})$

$1=$ Panjang bidang las $(\mathrm{m})$

\section{Uji Kinerja Alat}

Uji kinerja yang dilakukan meliputi kerapatan kamba, kapasitas teoritis, kapasitas aktual, daya aktual, efisiensi alat, anthropometri, tingkat kebisingan dan tingkat getaran (SNI 19-7029-2004).

\section{Kerapatan Kamba}

Kerapatan kamba atau bulk density dipakai untuk menghitung kapasitas teoritis dan menghitung banyaknya sampah yang dimasukkan ke dalam alat reaktor kompos, kerapatan kamba dapat dihitung dengan menggunakan Persamaan 10.

Kerapatan kamba $=\frac{\mathrm{W}_{\mathrm{d}}}{\mathrm{V}}$

Dimana:

$W_{d}=$ Massa sampah $(\mathrm{kg})$

$\mathrm{V}=$ Volume bak yang digunakan $\left(\mathrm{m}^{3}\right)$

\section{Kapasitas Teoritis}

Kapasitas teoritis merupakan kemampuan mesin untuk mengaduk sampah per satuan waktu (kg/jam) yang diketahui berdasarkan perhitungan dengan Persamaan 11 (Srivastava, et al., 2006).

$K_{t}=\rho \cdot N \cdot \pi(r)^{2} \cdot 1$

Dimana:

$\mathrm{K}_{\mathrm{t}}=$ Kapasitas teoritis $(\mathrm{kg} / \mathrm{jam})$

$\rho=$ densitas sampah organik kering $\left(\mathrm{kg} / \mathrm{m}^{3}\right)$

$\mathrm{N}=$ kecepatan putar silinder reaktor $(\mathrm{rpm})$

$\mathrm{r}=$ jari - jari silinder reaktor $(\mathrm{m})$

1 = panjang silinder reaktor $(\mathrm{m})$

\section{Kapasitas Aktual}

Kapasitas aktual adalah perbandingan antara berat total sampah yang yang telah menjadi kompos per satuan waktu. Adapun 
persamaan kapasitas aktual ditunjukkan oleh Persamaan 12.

$\mathrm{K}_{\mathrm{a}}=\frac{\mathrm{w}_{\mathrm{p}}}{\mathrm{t}}$

Dimana:

$\mathrm{K}_{\mathrm{a}}=$ Kapasitas pencampuran aktual ( $\left.\mathrm{kg} / \mathrm{jam}\right)$

$\mathrm{W}_{\mathrm{p}}=$ Berat total sampah $(\mathrm{kg})$

$\mathrm{t} \quad=$ Waktu yang dibutuhkan (jam)

\section{Efisiensi}

Efisiensi alat rektor kompos diperoleh dari perbandingan antara kapasitas aktual dengan kapasitas teoritis. Efisiensi dapat dihitung dengan Persamaan 13 (Nurmianto, 1991).

$\mathrm{Ef}=\frac{\mathrm{K}_{\mathrm{a}}}{\mathrm{K}_{\mathrm{t}}} \cdot 100 \%$

Dimana:

$\mathrm{Ef}=$ Efisiensi mesin $(\%)$

$\mathrm{Ka}=$ Kapasitas aktual $(\mathrm{kg} / \mathrm{jam})$

$\mathrm{Kt}=$ Kapasitas teoritis $(\mathrm{kg} / \mathrm{jam})$

\section{Daya Aktual}

Untuk dapat menentukan klasifikasi beban kerja berdasakan peningkatan detak jantung yang dibandingkan dengan detak jantung maskimum karena beban kardiovaskuler (cardiovasiculair $=\% \mathrm{CVL}$ ) dapat dihitung dengan menggunakan Persamaan 14.

$\% \mathrm{CVL}=\frac{D_{n k}-D_{n i}}{D_{n k}-D_{n i}} \times 100 \%$

Dimana:

$\mathrm{D}_{\mathrm{nk}}=$ Denyut Nadi Kerja

$\mathrm{D}_{\mathrm{ni}}=$ Denyut Nadi Istirahat

$\mathrm{D}_{\mathrm{nm}}=$ Denyut Nadi Maksimum

Detak jantung maksimum laki-laki adalah 220 dikurangi umur dan untuk wanita 200 dikurangi umur. Hasil dari perhitungan $\%$ CVL kemudian dibandingkan dengan klasifikasi yang telah ditetapkan sebagai berikut:
1. $<30 \%=$ Tidak terjadi kelelahan

2. $30-<60 \%=$ Diperlukan perbaikan

3. $60-<80=$ Kerja dalam waktu singkat

4. $80-<100 \%=$ Diperlukan tindakan segera

5. $>100 \%=$ Tidak diperbolehkan beraktivitas

Metode pengukuran beban kerja fisik secara langsung yaitu dengan mengukur energi yang dikeluarkan (energi expenditure) melalui asupan oksigen selama bekerja (Kilbon, 1992). Semakin berat beban kerja akan semakin banyak energi yang diperlukan untuk dikonsumsi. Dalam melakukan sebuah pekerjaan. Penentuan konsumsi energi biasanya digunakan suatu bentuk hubungan energi dengan kecepatan denyut jantung yaitu sebuah persamaan regresi kuadratis yang ditunjukkan pada Persamaan 15.

$E=1,80411-0,0229038 X+4,71733 \times 10^{-4} X^{2} \ldots$

Dimana:

$\mathrm{E}=$ Energi (kkal/menit)

$\mathrm{X}=$ Kecepatan denyut jantung/nadi

(denyut/menit)

Setelah didapat asupan energi, kemudian dihitung konsumsi energi dengan Persamaan 16 (Kilbon, 1992).

$$
\mathrm{K}=\mathrm{Et}-\mathrm{Ei}
$$

Dimana:

$\mathrm{K}=$ Konsumsi energi (kkal/menit)

$\mathrm{Et}=$ Pengeluaran energi pada saat melakukan kerja (kkal/menit)

Ei $=$ Pengeluaran energi pada saat istirahat (kkal/menit)

\section{Tingkat Kebisingan}

Kebisingan merupakan salah satu komponen yang menjadi parameter kenyamanan pada saat reaktor kompos portable dioperasikan. Pengukuran kebisingan dilakukan dengan menggunakan 
alat sound level meter. Berdasarkan SNI 45112011 mengenai kebisingan, dalam pengujian kinerja reaktor pengukuran dilakukan pada jarak $1 \mathrm{~m}$ dari sumber bunyi (Menteri Tenaga Kerja RI, 2011). Hal ini dilakukan karena akan menentukan kenyamanan dari operator saat mengoperasikan reaktor. Semakin besar kebisingan yang ditimbulkan oleh alat reaktor menyebabkan operator tidak nyaman dan dalam jangka waktu yang lama akan mengakibatkan gangguan pendengaran pada operator.

\section{Tingkat Getaran}

Getaran terjadi saat alat reaktor kompos dioperasikan, baik saat ada beban maupun saat tidak ada beban. Pengukuran tingkat getaran pada reaktor dilakukan menggunakan vibration meter pada komponen reaktor yang dekat dengan silinder reaktor kompos (Menteri Tenaga Kerja RI, 2011).

\section{Lama Waktu Pembuatan Kompos}

Pembuatan kompos dilakukan dengan tiga perlakuaan yang berbeda. Perlakuan pertama yaitu dengan pengadukan dan penambahan pupuk organik cair. Penambahan pupuk organik cair ini adalah untuk menambah $\mathrm{C}: \mathrm{N}$ ratio sesuai dengan $\mathrm{SNI}$ Kompos (SNI 19-7030-2004) yaitu 10:1. (Standar Nasional Indonesia, 2004) Perlakuan kedua yaitu sampah organik hanya dengan pengadukan saja, hal ini dilakukan untuk melihat perbedaan dengan tidak adanya penambahan pupuk organik. Perlakuan ketiga, yaitu sampah organik tidak mengalami pengadukan; perlakuan ini untuk membandingkan hasil dari perlakuaan pertama dan kedua yang mendapat pengadukan. Berdasarkan SNI Kompos (SNI 19-7030-2004), kematangan kompos dapat ditunjukkan oleh beberapa hal, yaitu berwarna kehitaman, tekstur seperti tanah dan berbau tanah.

\section{HASIL DAN PEMBAHASAN}

\section{Analisis Unit Transmisi}

Berdasarkan hasil perhitungan Persamaan 5, diperoleh panjangnya rantai yang dibutuhkan $0,703 \mathrm{~m}$. Panjang aktual rantai yang digunakan pada reaktor kompos portable sepanjang $1 \mathrm{~m}$ seperti yang disajikan pada Gambar 2.

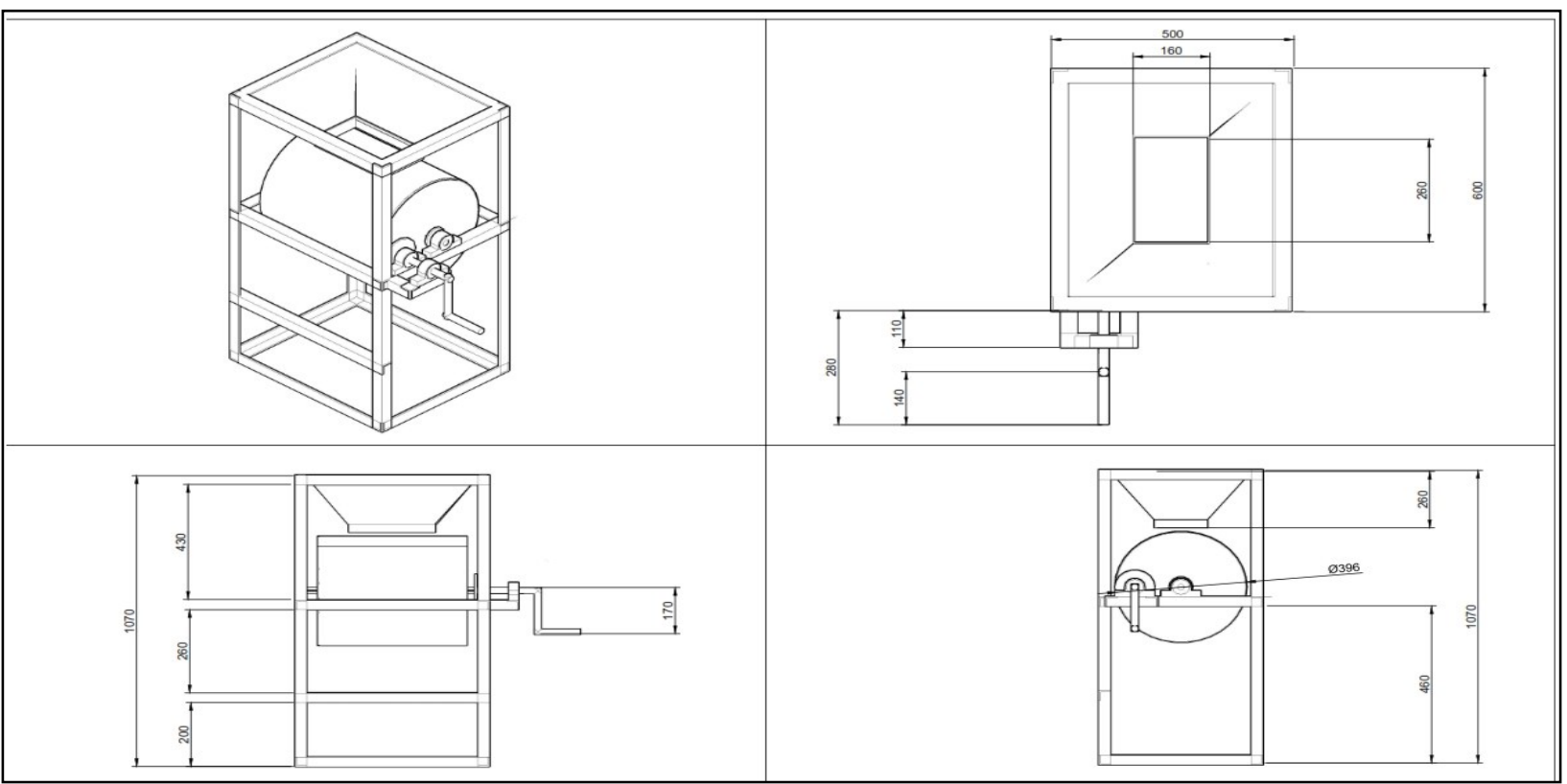

Gambar 2. Gambar proyeksi reaktor kompos 
Adapun tingkat kelayakan panjang rantai seperti yang tersaji pada Tabel 1. Secara teknis panjang rantai aktual lebih panjang dari hitungan teoritis, sehingga layak untuk digunakan.

Tabel 1. Perbandingan panjang rantai yang tersedia dengan hasil perhitungan

\begin{tabular}{cccc}
\hline Parameter & Aktual & Teoritis & Kelayakan \\
\hline & & & Panjang \\
& & & Rantai \\
Panjang & $1 \mathrm{~m}$ & $0,703 \mathrm{~m}$ & $\begin{array}{c}\text { Aktual } \geq \\
\text { Panjang } \\
\text { Rantai }\end{array}$ \\
& & & Rantai \\
& & & Teoritis \\
\hline
\end{tabular}

\section{Analisis Poros}

Hasil perhitungan teoritis diameter poros berdasarkan Persamaan 1 adalah $20 \mathrm{~mm}$ (Tabel 2). Sedangkan yang terpasang adalah $22 \mathrm{~mm}$, sehingga secara teknis diamater tersebut sesuai perhitungan minimal diameter terpasang. Poros berperan penting saat mesin digunakan, karena poros berfungsi untuk meneruskan daya dari operator menuju silinder reaktor kompos.

Tabel 2. Perbandingan poros yang tersedia dengan hasil perhitungan

\begin{tabular}{cccc}
\hline Parameter & Aktual & Teoritis & Kelayakan \\
\hline \multirow{3}{*}{ Poros } & & & Poros \\
& \multirow{2}{*}{$22 \mathrm{~mm}$} & $20 \mathrm{~mm}$ & $\begin{array}{c}\text { Tersedia } \geq \\
\text { Perhitungan } \\
\end{array}$ \\
& & & Teoritis \\
\hline
\end{tabular}

\section{Analisis Bantalan}

Adapun bantalan yang digunakan adalah bantalan gelinding tipe P204. Umur nominal dari bantalan berdasarkan persamaan 3 adalah 2139 jam (Tabel 3). Faktor yang menentukan lamanya umur bantalan diantaranya adalah besarnya beban yang ditumpu, jenis bantalan, dan kecepatan putar poros mesin. Umur nominal bantalan menunjukkan batas waktu maksimal pemakaian dari bantalan agar tetap berfungsi optimal.

Tabel 3. Hasil perhitungan umur nominal bantalan

\begin{tabular}{cccc}
\hline Parameter & Teoritis & Syarat & Kelayakan \\
\hline Umur & & $2000-$ & Umur \\
Nominal & \multirow{2}{*}{2139} & 4000 & Teoritis \\
Bantalan & & jam & $\geq$ Syarat \\
\hline
\end{tabular}

Sumber: Sularso \& Suga (1978)

\section{Analisis Kekuatan Rangka}

Reaktor kompos portable ini menggunakan rangka yang terbuat dari besi siku $3 \times 3 \mathrm{~mm}$ dengn ketebalan $3 \mathrm{~mm}$ dan besi hollow. Reaktor kompos portable ini memiliki dimensi keseluruhan $60 \mathrm{~cm}$ x $50 \mathrm{~cm}$ x 106,5 $\mathrm{cm}$. Rangka pada reaktor kompos portable menerima beban sebesar 20,273 kg (198,88 N) pada rangka yang terdiri dari beban hopper, bearing, rantai, silinder reaktor, gear, poros, dan sampah oranik kering dengan nilai lendutan berdasarkan Persamaan 6 sebesar $4,03 \times 10^{-8} \mathrm{~mm}$ (Tabel 4).

Tabel 4. Perbandingan lendutan yang terjadi pada rangka penahan silinder

\begin{tabular}{cccc}
\hline Parameter & Teoritis & Aktual & Kelayakan \\
\hline \multirow{4}{*}{ Lendutan } & 3,55 & $4,03 \mathrm{x}$ & Lendutan \\
& $\mathrm{mm}$ & $10^{-8} \mathrm{~mm}$ & $\begin{array}{c}\text { Teoritis } \geq \\
\text { Lendutan } \\
\text { Aktual }\end{array}$ \\
\hline
\end{tabular}

Berdasarkan hasil perhitungan Persaman 6, lendutan yang terjadi pada rangka memiliki nilai yang lebih kecil dibandingkan dengan batas nilai yang diizinkan. Oleh karena itu, rangka yang digunakan pada reaktor kompos portable ini sudah layak dan aman untuk digunakan.

\section{Analisis Kekuatan Las}

Rangka alat reaktor kompos portable yang menumpu komponen mesin lainnya dibangung dengan cara dilas. Adapun jenis las yang digunakan pada pembangunan rangka mesin reaktor kompos portable ini adalah tipe las sambung (butt joint). Beban yang ditopang oleh sambungan las yang terletak di titik sudut rangka penahan silinder berdasarkan Persamaan 9 adalah 20,273 kg (198,88 N). Adapun ukuran tebal bidang las adalah $3 \mathrm{~mm}$ dan panjang bidang las $36 \mathrm{~mm}$. 
Tabel 5. Perbandingan kekuatan las secara aktual dengan teoritis

\begin{tabular}{cccc}
\hline Parameter & Teoritis & Aktual & Kelayakan \\
\hline \multirow{2}{*}{ Beban } & \multirow{2}{*}{$6048 \mathrm{~N}$} & $\begin{array}{c}198,88 \\
\mathrm{~N}\end{array}$ & $\begin{array}{c}\text { F Teoritis } \geq \\
\text { F Aktual }\end{array}$ \\
\hline
\end{tabular}

Secara keseluruhan, beban yang diterima sambungan las pada rangka memiliki nilai yang lebih kecil dari beban yang diizinkan oleh sambungan. Sehingga sambungan las (Tabel 5) pada rangka reaktor kompos portable ini layak dan aman untuk dapat menopang beban yang diterima.

\section{Kelayakan Analisis Teknik}

Kelayakan analisis teknik dapat diketahui dengan membandingkan perhitungan secara teoritis setiap komponen yang ada pada mesin dengan pengukuran secara aktual pada mesin (Tabel 6). Apabila hasil pengukuran sudah sesuai dengan hasil hitungan secara teoritis dan memenuhi standar yang sudah ditetapkan maka komponen mesin tersebut dikatakan layak dan dapat digunakan.

Tabel 6. Kelayakan teknis reaktor kompos portable (RK-TEP-1401)

\begin{tabular}{|c|c|c|c|c|}
\hline Parameter & Aktual & $\begin{array}{l}\text { Teoritis Hasil } \\
\text { Perhitungan }\end{array}$ & Kriteria Kelayakan & Kesimpulan \\
\hline \multicolumn{5}{|c|}{ UNIT TRANSMISI } \\
\hline Panjang rantai & $1 \mathrm{~m}$ & $0,703 \mathrm{~m}$ & $\begin{array}{c}\text { Panjang aktual } \geq \\
\text { panjang teoritis }\end{array}$ & Memenuhi \\
\hline \multicolumn{5}{|c|}{ POROS } \\
\hline Diameter Poros & $22 \mathrm{~mm}$ & $20 \mathrm{~mm}$ & $\begin{array}{c}\text { Poros tersedia } \geq \\
\text { perhitungan teoritis }\end{array}$ & Memenuhi \\
\hline \multicolumn{5}{|c|}{ BANTALAN } \\
\hline $\begin{array}{c}\text { Umur Nominal } \\
\text { Bantalan }\end{array}$ & 2139 jam & 2000-4000 jam & $\begin{array}{c}\text { Umur aktual } \geq \text { umur } \\
\text { teoritis }\end{array}$ & Memenuhi \\
\hline \multicolumn{5}{|c|}{ RANGKA } \\
\hline Rangka & $4,03 \times 10^{-8} \mathrm{~mm}$ & $3,55 \mathrm{~mm}$ & $\begin{array}{c}\text { Lendutan aktual } \leq \\
\text { lendutan teoritis yang } \\
\text { diizinkan. }\end{array}$ & Memenuhi \\
\hline \multicolumn{5}{|c|}{ LAS } \\
\hline $\begin{array}{l}\text { Beban yang ditopang } \\
\text { rangka }\end{array}$ & $198,878 \mathrm{~N}$ & $6048 \mathrm{~N}$ & $\begin{array}{l}\text { Beban aktual } \leq \text { beban } \\
\text { teoritis yang diizinkan. }\end{array}$ & Memenuhi \\
\hline
\end{tabular}

Tabel 6 menunjukkan rekapitulasi hasil analisis teknik yang telah dilakukan menunjukkan 6 parameter telah memenuhi kriteria yang ditetapkan, yaitu panjang rantai (1 meter) lebih panjang dari hitungan teoritis $(0,703 \mathrm{~m})$, diameter poros aktual $(22 \mathrm{~mm})$ lebih besar dari hitungan teoritis $(20 \mathrm{~mm})$, umur nominal bantalan (2139 jam) masih di kisaran 2000 - 4000 jam, lendutan pada rangka $\left(4,03 \times 10^{-8} \mathrm{~mm}\right)$ lebih kecil dibandingkan dengan lendutan yang diizinkan $(3,55 \mathrm{~mm})$, beban aktual hasil las $(198,9 \mathrm{~N})$ masih lebih kecil dari beban las yang diizinkan $(6048 \mathrm{~N})$.

\section{Uji Kinerja}

Kerapatan Kamba

Perhitungan kerapatan kamba dimulai dengan memasukkan sampah organik kering ke dalam bak kayu dengan volume $0,032 \mathrm{~m}^{3}$ untuk ditimbang. Sampah organik dimasukkan sampai memenuhi volume bak kayu dengan 5 kali ulangan. Berdasarkan hasil pengukuran pada Persamaan 10, nilai bulk density rata - rata dari sampah organik daun kering sebesar $247,20 \mathrm{~kg} / \mathrm{m}^{3}$. Nilai tersebut sebagai variabel untuk menghitung kapasitas teoritis 


\section{Kapasitas Teoritis}

Berdasarkan perhitungan pada Persamaan 11, diperoleh bahwa nilai kapasitas teoritis alat reaktor kompos portable adalah $1439,20 \mathrm{~kg} / \mathrm{jam}$.

\section{Kapasitas Aktual}

Berdasarkan perhitungan Persamaan 12, kapasitas aktual reaktor kompos adalah 921,6 $\mathrm{kg} / \mathrm{jam}$. Selain dipengaruhi oleh keterampilan operator, kapasitas aktual juga dipengaruhi oleh luas area pemasukan bahan melalui hopper dan kecepatan putar agitator yang dilakukan oleh operator. Semakin besar luas area pemasukan bahan pada hopper dan semakin cepat operator memutarkan agitator, maka kapasitas aktual reaktor dapat menjadi semakin besar juga.

\section{Efisiensi Reaktor}

Berdasarkan hasil perhitungan pada persamaan 13 didapatkan efisiensi dari reaktor kompos portable ini adalah sebesar 64\%. Nilai tersebut kecil bila dibandingkan dengan reaktor kompos menggunakan motor penggerak motor listrik, hal ini karena alat masih dioperasikan secara manual.

\section{Kebutuhan Daya Aktual}

Perhitungan kebutuhan daya penggerak dengan mengunakan metode pengukuran beban kerja fisik secara langsung yaitu dengan mengukur energi yang dikeluarkan (energi expenditure) melalui suplai oksigen selama bekerja. Pengukuran konsumsi energi didapatkan mengoperasikan alat reaktor kompos ini. Konsumsi energi merupakan hasil pengurangan dari konsumsi energi saat melakukan pekerjaan dikurangi konsumsi energi saat istirahat. Berdasarkan Persamaan 16, perhitungan total beban kerja saat ada beban sebesar 215,94 Watt dan saat tidak ada beban sebesar 87,5 Watt. Nilai tersebut diperoleh hanya sebatas menggunakan tenaga tangan operator pada saat memutar agitator secara manual.

\section{Lama Waktu Pembuatan Kompos}

Pembuatan kompos dilakukan dengan tiga perlakuan yang berbeda. Perlakuan satu, yaitu dengan pengadukan dan penambahan pupuk organik cair. Penambahan pupuk organik cair ini adalah untuk menambah $\mathrm{C}: \mathrm{N}$ ratio sesuai dengan SNI Kompos (SNI 197030-2004) yaitu 10:1. Perlakuan dua, yaitu sampah organik hanya dengan pengadukan saja, hal ini dilakukan untuk melihat perbedaan dengan tidak adanya penambahan pupuk organik. Perlakuan ketiga yaitu sampah organik tidak mengalami pengadukan, untuk membandingkan hasil dari perlakuan 1 dan 2 yang mendapat pengadukan.

Tabel 7. Hasil pembuatan kompos dari sampah organik kering

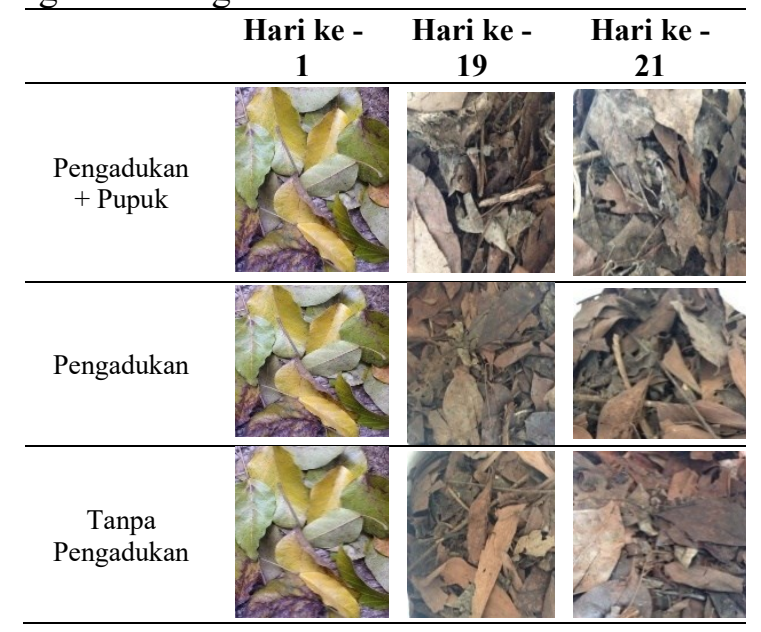

Adapun pengamatan dilakukan di hari ke-19 dan hari ke-21. Pada perlakuan pertama, setelah dicek di hari ke-21, warna kompos sudah berubah kehitaman, tekstur sudah remah seperti tanah, dan berbau tanah. Berdasarkan SNI Kompos (SNI 19-70302004), kematangan kompos dapat ditunjukkan oleh beberapa hal, yaitu berwarna kehitaman, tekstur seperti tanah, dan berbau tanah.

Pada perlakuan 1, yaitu dengan pengadukan dan penambahan pupuk cair organik, kompos yang dihasilkan berwarna kehitaman dan berbau tanah yang lebih menyengat. Pada perlakuan 2, yaitu dengan pengadukan saja, kompos yang dihasilkan 
berwarna kehitaman dan berbau tanah. Hal ini serupa dengan perlakuan 3, yaitu dengan tidak adanya pengadukan pada sampah organik kering, kompos berwarna kehitaman dan berbau tanah (Tabel 7).

\section{Tingkat Kebisingan}

Berdasarkan hasil pengukuran dengan alat sound level meter, rata-rata tingkat kebisingan adalah 62,63 dB (Tabel 8). Tingkat kebisingan reaktor kompos portable masih di bawah syarat uji yang diizinkan, yaitu sebesar $90 \mathrm{~dB}$ sehingga kebisingan yang terjadi tidak terlalu menganggu operator dan masih dalam kondisi aman. Hasil ini lebih rendah daripada penelitian Nugraha, et al., (2019) yang menghasilkan mesin pencacah sampah organik dengan tingkat kebisingan $90 \mathrm{~dB}$. Dengan rata-rata tingkat kebisingan maksimum 62,63 dB, maka jam kerja yang diijinkan berdasarkan OSHA 1910.95 tidak melebihi 8 jam kerja/hari (OSHA, n.d.).

Tabel 8. Perbandingan tingkat kebisingan pada reaktor kompos portable (RK TEP-1401) dengan syarat uji

\begin{tabular}{cccc}
\multicolumn{2}{c}{ Tingkat Kebisingan } & & \\
$(\mathbf{d B})$ & Syarat & \\
\cline { 1 - 2 } Tidak & Ada & $\begin{array}{c}\text { Uji } \\
\text { (dB) }\end{array}$ & Kelayakan \\
Ada & Beban & & \\
Beban & & $<90$ & Aman \\
\hline 60,53 & 62,63 & $<$ \\
\hline
\end{tabular}

\section{Tingkat Getaran}

Rata-rata tingkat getaran reaktor kompos portable saat tidak dioperasikan dan pada saat dioperasikan adalah sebesar 3,6 $\mathrm{mm} / \mathrm{s}$ dan $4,4 \mathrm{~mm} / \mathrm{s}$ (Tabel 9). Nilai ini tidak melebihi ambang batas yang diizinkan untuk reaktor $(0,7 \mathrm{~mm} / \mathrm{s}-4,5 \mathrm{~mm} / \mathrm{s})$ dan termasuk dalam kategori aman, baik saat tidak ada beban, maupun saat ada beban. Meskipun tingkat getaran reaktor kompos portable di bawah syarat uji yang diizinkan $(4,5 \mathrm{~mm} / \mathrm{s})$, getaran yang terjadi dirasakan cukup menganggu operator. Salah satu solusi untuk menurunkan tingkat getaran adalah dengan cara menambahkan bantalan karet di bawah kaki rangka alat reaktor kompos.

Tabel 9. Perbandingan tingkat kebisingan pada reaktor kompos portable (RK TEP-1401) dengan syarat uji

\begin{tabular}{cccc}
\hline \multicolumn{2}{c}{$\begin{array}{c}\text { Tingkat Getaran } \\
(\mathrm{mm} / \mathrm{s})\end{array}$} & $\begin{array}{c}\text { Syarat Uji } \\
(\mathrm{mm} / \mathrm{s})\end{array}$ & Kelayakan \\
\cline { 1 - 2 } $\begin{array}{c}\text { Tidak Ada } \\
\text { Beban }\end{array}$ & $\begin{array}{c}\text { Ada } \\
\text { Beban }\end{array}$ & & \\
\hline 3,6 & 4,4 & $0,7-4,5$ & Aman \\
\hline
\end{tabular}

\section{KESIMPULAN}

Hasil perhitungan analisis teknik menunjukkan bahwa spesifikasi dari Alat Reaktor Kompos Portable (RK TEP-1401) adalah diameter poros $22 \mathrm{~mm}$, umur nominal bantalan 721.397 jam, panjang rantai yang dibutuhkan $0,703 \mathrm{~m}$, lendutan pada rangka $4,03 \times 10^{-8} \mathrm{~mm}$, dan kekuatan las untuk menopang beban 198,88 $\mathrm{N}$ telah memenuhi syarat uji, sehingga layak untuk digunakan. Berdasarkan hasil uji kinerja, didapatkan kerapatan kamba $247,20 \mathrm{~kg} / \mathrm{m}^{3}$, kapasitas teoritis $1.439,20 \mathrm{~kg} / \mathrm{jam}$, kapasitas aktual $921,6 \mathrm{~kg} / \mathrm{jam}$, efisiensi reaktor $64,03 \%$ dan kebutuhan daya aktual 215,94 Watt. Selain itu, alat menghasilkan tingkat kebisingan reaktor sebesar $62,63 \mathrm{~dB}$ dan tingkat getaran reaktor $4,4 \mathrm{~mm} / \mathrm{s}$.

\section{DAFTAR REFERENSI}

Crawford. (2003). Composting of Agricultural waste in biotechnology. Biotechnology Applications and Research, Paul N, Cheremisinoff and R. P. Ouellette (ed).

Kastaman, K. (2007). Perancangan Reaktor Sampah Terpadu Dengan Pengembangan Mikroba Penghilang Bau Sampah Dalam Rangka Mengatasi Masalah Sampah di Perkotaan. LPPM Unpad. 
Kilbon. (1992). Measurement and Assessment of Dynamic Work. Dalam: Evaluation of Human Work. A Practical Ergonomic Methodology, ed. By Wilson, JR dan Corlett, EN, Taylor and Francis. Taylor and Francis.

Menteri Tenaga Kerja RI. (2011). Peraturan Menteri Tenaga Kerja dan Transmigrasi Nomor PER. 13/MEN/X/2011. Kementerian Tenaga Kerja RI.

Nugraha, N., Pratama, D. S., Sopian, S., \& Roberto, N. (2019). Jurnal Rekayasa Hijau 3 (2), 169 - 178.

Nurmianto. (1991). Ergonomi Konsep Dasar dan Aplikasinya. Guna Widya.

OSHA. (n.d.). Occupational Safety \& Health Administration. Retrieved from U.S. Department of Labor: https://www.osha.gov/lawsregs/regulations/standardnumber/191 0/1910.95.

Singer, F. L., Andrew, P., \& Darwin, S. (1995). Kekuatan Bahan (Teori kokoh_strenght of Material). Erlangga.

Srivastava, A. K., Goering, C. E, Rohrbach, R. P., \& Buckmaster, D. R. (2006). Engineering Principles of Agricultural Machines. American Society of Agricultural and Biological Engineers.

Standar Nasional Indonesia. (2004). Spesifikasi Kompos dari Sampah Organik Domestik. SNI No.19-70302004. Badan Standar Nasional.

Sularso \& Suga, K. (1978). Dasar Perencanaan dan Perancangan Elemen Reaktor. Pradnya Paramita. 